\title{
18-Month Clinical Comparison of Giomer Based and Nano Technology Based Materials in Non-Carious Cervical Lesion Class V Restorations
}

\author{
Kang YH*, Magnuson BE, Singh ML, Tran DL, Pagni SE, Perry RD and \\ Kugel G \\ Tufts University School of Dental Medicine, USA
}

*Corresponding author: Yoon H Kang, Tufts University School of Dental Medicine, 1 Kneeland St. DHS-748, Boston, MA 02111, USA, Tel: (617) 636-3843; Fax: (617) 6366511; Email: yoon.kang@tufts.edu

\section{Research Article \\ Volume 6 Issue 3}

Received Date: August 05, 2021

Published Date: August 19, 2021

DOI: $10.23880 /$ oajds-16000303

\section{Abstract}

The 18-month randomized, controlled, split mouth, clinical trial have been completed. Visits include: screening, restoration placement, 6 month follow-up and 18-month follow-up. Cervical lesions were restored with giomer based BEAUTIFIL II LS (SHOFU, Kyoto, Japan) (BL) or nano technology based Filtek ${ }^{\mathrm{TM}}$ Supreme (3M, St. Paul, MN) (FS). Restorations were placed following the manufacturer's guidelines. Clinical assessments were done by blinded examiners excluding the examiner that placed the restorations. Restorations were evaluated according to clinical criteria by Hickel, et al. including esthetic properties (surface luster, surface staining, marginal staining, color match, anatomical form), functional properties (fracture of material and retention, marginal adaptation, patient's view) and biologic properties (recurrence of caries, tooth integrity, adjacent mucosa). The Wilcoxon signed-rank test was used to compare the Hickel criteria between groups. Hickel scores were analyzed using the Wilcoxon signed-rank test. The Wilcoxon signed-rank test compared differences between the two groups (BL - FS) within the same subject and then ranked the differences. Only positive and negative ranks were used in the analysis. The established null hypothesis: BL and FS will perform equally in Hickel Scoring (H0: BL = FS) was not rejected as no Hickel criteria comparisons showed statistical significances. Clinical performance comparison of non-carious cervical lesion restorations between giomer and nano technology based restorative systems showed no statistical differences according to Hickel criteria with similar clinical evaluations for both restorative materials.

Keywords: Giomer; Nanohybrid; Nanofil composite; Nano technology; Dental materials; Class V restoration; Restorative dentistry; Clinical trial

Abbreviations: CEJ: Cemento-Enamel Junction; NCCL: Non-Carious Cervical Lesions; BL: Beautifil II LS; ADA: American Dental Association; ICF: Informed Consent Form; TUSDM: Tufts University School of Dental Medicine

\section{Introduction}

Loss of tooth structure at the cemento-enamel junction (CEJ), also referred as non-carious cervical lesions (NCCL), are commonly observed clinical conditions in dental practice [1]. These lesions are of a non-bacterial origin with higher prevalence among the ageing population where teeth are increasingly being retained for a lifetime [2]. The main etiology is mechanical abrasion resulting from abfraction of hard tissue at the CEJ [1,2]. A proposed etiology for loss of restorations in the cervical area is occlusion generated stresses that are concentrated at the cervical region and result in debonding, leakage, retention failure, and, ultimately, 
restorative failure [3]. The main clinical outcome is a loss of tooth structure, leading to weakened dentitions and presence of structural defects collecting plaque, and providing sites for harboring of bacteria. Depending on the severity of structural loss, tooth hypersensitivity may also occur and pulp vitality is affected by the plaque bacterial source [4]. Another important clinical factor is esthetics. Cervical lesions with defects at CEJ pose compromised esthetics, therefore, restoring the normal structural anatomy is an important motivation in Class $\mathrm{V}$ restorations. Methacrylate-based composites are considered the gold-standard for direct restorative procedures due to superior esthetic as well as mechanical properties as compared to glass-ionomer cements or hybrid-ionomers [5]. With the new understanding on etiology of NCCL and Class V restorations, clinical approaches that combine chemical adhesion and restorative materials of appropriate mechanical properties- specifically fracture toughness and elasticities- show promise of long-term success [3].

Clinically, cavity preparation for typical non-carious cervical lesions hinders creating retention shape due to the limited amount of healthy tooth structure between the surface of cervical lesion to pulp [6,7]. Therefore, often the cavity preparation is limited to removing sclerotic dentin for optimal surface condition for bonding agents with minimal overall tooth structure removal [6,7]. Unlike other G.V. Black based cavity preparations, Class $\mathrm{V}$ resin composite based restorations almost solely rely on enamel/dentin bonding strength for the retention of the restorative material. Selection of optimal materials to generate the best clinical outcomesincluding restoration of esthetics, prevention of further tooth structure loss from abfractions and erosion, and insulating and protecting pulp- is one of the critical decisions for the clinicians. In this study, we compared two resin composite direct restoration materials that offer various advantages with respective bonding systems for the treatment of NCCL clinical conditions.

One system used in this study is a nano-hybrid restorative material, Beautifil II LS (BL) and Beautibond by Shofu (Shofu, Kyoto, Japan). BL is formulated with polymer matrix composition of Low shrinkage Urethane diacrylate (UDMA),
Bis-MPEPP (Bisphenol A polyethoxy Methacrylate) BisGMA (Bis-phenol A diglycidylmethacrylate) and TEGDMA (Triethylenglycol dimethacrylate) [8]. The main feature of this restorative material is the bioactive surface pre-reacted glass-ionomer (S-PRG) filler, with a combination of polymer matrix and filler reported to yield low volumetric shrinkage $(0.85 \%)$ (normal range $2-5 \%$ ) and shrinkage stress $(10.9$ $\mathrm{MPa}$ ) [9]. Giomer is a collective term for dental materials which incorporate S-PRG filler. S-PRG filler is capable of releasing 6 types of ions $(\mathrm{Na}+, \mathrm{Sr} 2+, \mathrm{Al} 3+, \mathrm{F}-, \mathrm{BO} 33-$ and SiO32-), these multiple ions potentially provide bioactive effects (strengthening of tooth structure, anti-plaque effect, dentin remineralization, acid-buffering capacity, inhibition of enzymatic activity of periodontal pathogenic bacteria, etc.) [10]. The bonding system Beautibond, which is acetone/ water solvent based, consists of phosphonic acid (which is more stable than phosphoric acid) monomer and carboxylic acid monomer that are optimal for enamel and dental bonding, respectively [10].

Nano technology based direct restoration materials have shown success in clinical applications [11]. In this study, the giomer system is compared to the true nano technology based system, 3M/ESPE Filtek Supreme Universal Restortative (FS) with Scotchbond ${ }^{\mathrm{TM}}$ Universal Adhesive by 3M (3M, St. Paul, MN). FS is a bis-GMA, UDMA, TEGDMA and bis-EMA-6 (Bisphenol A polyethethylene glycol diether dimethacrylate) resin with PEGDMA (poly (ethylene glycol) dimethacrylate) substituted for a portion of the TEGDMA for reducing shrinkage rate [12]. The key feature of this nano technology is non-agglomerated/non-aggregated silica filler $(20 \mathrm{~nm})$, nonagglomerated/non-aggregated zirconia filler (4 to $11 \mathrm{~nm}$ ), and aggregated zirconia/silica cluster filler [12]. This nano technology based material is reported to display superior shade, wear resistance, polishing ability, and good minimal shrinkage at $2 \% \mathrm{v} / \mathrm{v}$ [12]. The bonding system with this restoration material is $3 \mathrm{M}^{\mathrm{TM}}$ Scotchbond ${ }^{\mathrm{TM}}$ Universal Adhesive containing Vitrebond ${ }^{\mathrm{TM}}$ methacrylate-modified polyalkenoic acid copolymer in ethanol based hydrophilic solvent [13]. The key ingredients of both restorative materials are listed and compared in Table 1.

\begin{tabular}{|c|c|}
\hline Shofu BL II LS & 3M FS Supreme Universal [12] \\
\hline $\begin{array}{c}\text { Bisphenol A glycidyl dimethacrylate, TEGDMA, } \\
\text { inorganic glassfiller, aluminuoxide, silica, pre-reacted } \\
\text { glass ionomer filler, DL-camphorquinone }\end{array}$ & $\begin{array}{c}\text { bis-GMA, UDMA, TEGDMA, and bis-EMA(6) non-agglomerated/non- } \\
\text { aggregated 20nm silica filler, non-agglomerated/non-aggregated } \\
\text { zirconia filler, and aggregated zirconia/silica cluster filler }\end{array}$ \\
\hline BeautiBond [10] & 3M Scotch Universal Bond [13] \\
\hline $\begin{array}{c}\text { Acetone, Bis-GMA, TEGDMA, Phosphonic acid } \\
\text { monomer Carboxylic acid monomer Water. HEMA free }\end{array}$ & $\begin{array}{c}\text { MDP Phosphate Monomer, Dimethacrylate resins, HEMA, Vitrebond } \\
\text { Copolymer, Filler, Ethanol, Water, Initiators, Silane }\end{array}$ \\
\hline
\end{tabular}

Table 1: Material Composition and Comparisons. 


\begin{tabular}{|c|c|c|c|c|c|c|}
\hline & & $\begin{array}{l}\text { 1. Clinically } \\
\text { excellent / very } \\
\text { good }\end{array}$ & $\begin{array}{l}\text { 2. Clinically good (after } \\
\text { polishing probably } \\
\text { very good) }\end{array}$ & $\begin{array}{c}\text { 3. Clinically sufficient/ } \\
\text { Satisfactory (minor } \\
\text { shortcomings, no } \\
\text { unacceptable effects but not } \\
\text { adjustable w/o damage to } \\
\text { the tooth) }\end{array}$ & $\begin{array}{l}\text { 4. Clinically } \\
\text { unsatisfactory (but } \\
\text { repairable) }\end{array}$ & $\begin{array}{l}\text { 5. Clinically poor } \\
\text { (replacement } \\
\text { necessary) }\end{array}$ \\
\hline \multirow{8}{*}{ 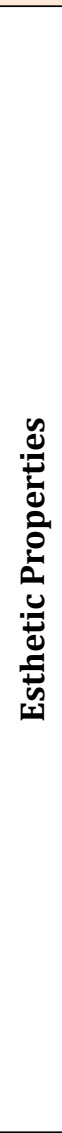 } & \multirow[t]{2}{*}{ Surface Luster } & \multirow[t]{2}{*}{$\begin{array}{l}\text { 1. Luster } \\
\text { comparable to } \\
\text { enamel }\end{array}$} & $\begin{array}{l}2.1 \text { Slightly dull, } \\
\text { not noticeable from } \\
\text { speaking distance. }\end{array}$ & $\begin{array}{l}\text { 3.1 Dull surface but acceptable } \\
\text { if covered with film of saliva. }\end{array}$ & $\begin{array}{l}\text { 4.1 Rough surface, cannot } \\
\text { be masked by saliva } \\
\text { film, simple polishing is } \\
\text { not sufficient. Further } \\
\text { intervention necessary. } \\
\end{array}$ & \multirow[t]{2}{*}{$\begin{array}{l}\text { 5.Very rough, } \\
\text { unacceptable plaque } \\
\text { retentive surface. }\end{array}$} \\
\hline & & & 2.2 Some isolated pores. & $\begin{array}{l}\text { 3.2 Multiple pores on more } \\
\text { than one third of surface }\end{array}$ & 4.2 Voids. & \\
\hline & Surface Staining & $\begin{array}{l}\text { 1. No surface } \\
\text { staining }\end{array}$ & $\begin{array}{l}\text { 2. Minor surface } \\
\text { staining, easily } \\
\text { removable by polishing }\end{array}$ & $\begin{array}{l}\text { 3. Moderate surface staining } \\
\text { that may also present on } \\
\text { other teeth, not esthetically } \\
\text { unacceptable }\end{array}$ & $\begin{array}{c}\text { 4. Unacceptable } \\
\text { surface staining on the } \\
\text { restoration and major } \\
\text { intervention necessary for } \\
\text { improvement } \\
\end{array}$ & $\begin{array}{l}\text { 5. Severe surface staining } \\
\text { and/or subsurface } \\
\text { staining, generalized or } \\
\text { localized, not accessible } \\
\text { for intervention } \\
\end{array}$ \\
\hline & Marginal Staining & $\begin{array}{l}\text { 1. No marginal } \\
\text { staining }\end{array}$ & $\begin{array}{l}\text { 2. Minor marginal } \\
\text { staining, easily } \\
\text { removable by polishing }\end{array}$ & $\begin{array}{l}\text { 3. Moderate marginal staining, } \\
\text { not esthetically unacceptable }\end{array}$ & $\begin{array}{l}\text { 4. Pronounced marginal } \\
\text { staining; major } \\
\text { intervention necessary for } \\
\text { improvement }\end{array}$ & $\begin{array}{l}\text { 5. Deep marginal } \\
\text { staining, not accessible } \\
\text { for intervention }\end{array}$ \\
\hline & \multirow{3}{*}{$\begin{array}{l}\text { Color Match and } \\
\text { Translucency }\end{array}$} & \multirow{3}{*}{$\begin{array}{l}\text { 1. Good color } \\
\text { match, no } \\
\text { difference in } \\
\text { shade and/or } \\
\text { translucency }\end{array}$} & \multirow{3}{*}{$\begin{array}{l}\text { 2. Minor deviations } \\
\text { in shade and/or } \\
\text { translucency }\end{array}$} & $\begin{array}{l}\text { 3. Distinct deviation but } \\
\text { acceptable. Does not affect } \\
\text { esthetics: }\end{array}$ & $\begin{array}{l}\text { 4. Localized clinically } \\
\text { deviation that can be } \\
\text { corrected by repair: }\end{array}$ & \multirow{3}{*}{$\begin{array}{l}\text { 5. Unacceptable. } \\
\text { Replacement necessary }\end{array}$} \\
\hline & & & & $\begin{array}{c}3.1 \text { more opaque } 3.2 \text { more } \\
\text { translucent }\end{array}$ & $\begin{array}{c}4.1 \text { too opaque } 4.2 \text { too } \\
\text { translucent }\end{array}$ & \\
\hline & & & & 3.3 darker 3.4 brighter & 4.3 too dark 4.4 too bright & \\
\hline & $\begin{array}{l}\text { Esthetic anatomical } \\
\text { form }\end{array}$ & 1. Form is ideal & $\begin{array}{l}\text { 2. Form is only slightly } \\
\text { deviated from the } \\
\text { normal }\end{array}$ & $\begin{array}{l}\text { 3. Form deviates from the } \\
\text { normal but is esthetically } \\
\text { acceptable }\end{array}$ & $\begin{array}{c}\text { 4. Form is affected and } \\
\text { unacceptable esthetically. } \\
\text { Intervention/correction is } \\
\text { necessary } \\
\end{array}$ & $\begin{array}{l}\text { 5. Form is unsatisfactory } \\
\text { and/or lost. Repair not } \\
\text { feasible/reasonable. } \\
\text { Replacement needed }\end{array}$ \\
\hline
\end{tabular}




\begin{tabular}{|c|c|c|c|c|c|c|}
\hline \multirow{13}{*}{ 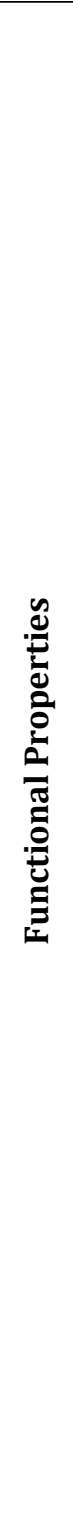 } & $\begin{array}{l}\text { Fracture of material } \\
\text { and retention }\end{array}$ & $\begin{array}{l}\text { 1. No fractures / } \\
\text { cracks }\end{array}$ & 2. Small hairline crack & $\begin{array}{c}\text { 3. Two or more or larger } \\
\text { hairline cracks and/or } \\
\text { material chip fracture not } \\
\text { affecting the marginal integrity } \\
\text { or proximal contact }\end{array}$ & \begin{tabular}{|c|}
$\begin{array}{c}\text { 4. Material chip fractures } \\
\text { which damage marginal } \\
\text { quality or approximal } \\
\text { contacts }\end{array}$ \\
$\begin{array}{c}\text { 4.2 Bulk fractures with } \\
\text { partial loss (less than half } \\
\text { of the restoration) }\end{array}$ \\
\end{tabular} & $\begin{array}{l}\text { 5. (Partial or complete) } \\
\text { loss of restoration or } \\
\text { multiple fractures }\end{array}$ \\
\hline & \multirow{4}{*}{ Marginal adaptation } & \multirow{4}{*}{$\begin{array}{l}\text { 1. Harmonious } \\
\text { outline, no gaps, } \\
\text { no white or } \\
\text { discolored lines }\end{array}$} & $\begin{array}{c}2.1 \text { Marginal gap }(<150 \\
\mu \mathrm{m}), \text { white lines }\end{array}$ & $\begin{array}{l}3.1 \mathrm{Gap}<250 \mu \mathrm{m} \text { not } \\
\text { removable }\end{array}$ & $\begin{array}{c}.1 \mathrm{Gap}>250 \mu \mathrm{m} \text { or } \\
\text { dentine/base exposed }\end{array}$ & $\begin{array}{c}5.1 \text { Restoration } \\
\text { (complete or partial) is } \\
\text { loose but in situ }\end{array}$ \\
\hline & & & 2.2 Small & $\begin{array}{l}\text { 3.2. Several small marginal } \\
\text { fractures }\end{array}$ & $\begin{array}{l}\text { 4.2. Severe ditching or } \\
\text { marginal fractures }\end{array}$ & $\begin{array}{l}5.2 \text { Generalized major } \\
\text { gaps or irregularities. }\end{array}$ \\
\hline & & & $\begin{array}{l}\text { marginal fracture } \\
\text { removable by polishing }\end{array}$ & 3.3 Major & $\begin{array}{l}\text { 4.3 Larger irregularities or } \\
\text { steps (repair necessary) }\end{array}$ & \\
\hline & & & $\begin{array}{l}\text { 2.3 Slight ditching, slight } \\
\text { step/flashes, minor } \\
\text { irregularities }\end{array}$ & $\begin{array}{l}\text { irregularities, ditching or } \\
\text { flash,steps }\end{array}$ & & \\
\hline & \multirow{4}{*}{$\begin{array}{c}\text { Radiographic } \\
\text { examination (when } \\
\text { applicable) }\end{array}$} & \multirow{4}{*}{$\begin{array}{l}\text { 1. No pathology, } \\
\text { Harmonious } \\
\text { transition between } \\
\text { restoration and } \\
\text { tooth }\end{array}$} & $\begin{array}{c}2.1 \text { Acceptable material } \\
\text { excess present. }\end{array}$ & 3. 1 Marginal gap $<250 \mu \mathrm{m}$. & 4.1 Marginal gap $>250 \mu \mathrm{m}$. & 5.1 Secondary \\
\hline & & & $\begin{array}{c}2.2 \text { Positive/negative } \\
\text { step present at margin } \\
<150 \mu \mathrm{m}\end{array}$ & $\begin{array}{c}\text { 3. } 2 \text { Negative steps visible }< \\
250 \mu \mathrm{m} \text {. No adverse effects } \\
\text { noticed. }\end{array}$ & $\begin{array}{l}\text { 4.2 Material excess } \\
\text { accessible but not } \\
\text { removable. }\end{array}$ & $\begin{array}{c}\text { caries, large gaps, large } \\
\text { overhangs }\end{array}$ \\
\hline & & & & $\begin{array}{l}\text { 3.3 Poor radiopacity of filling } \\
\text { material. }\end{array}$ & $\begin{array}{c}4.3 \text { Negative steps } \\
>250 \mu \mathrm{m} \text { and reparable }\end{array}$ & 5.2 Apical pathology \\
\hline & & & & & & $\begin{array}{l}5.3 \text { Fracture/loss of } \\
\text { restoration or tooth. }\end{array}$ \\
\hline & \multirow{4}{*}{ Subject's View } & \multirow{4}{*}{$\begin{array}{c}\text { 1. Entirely satisfied } \\
\text { with esthetics and } \\
\text { function. }\end{array}$} & 2. Satisfied. & $\begin{array}{l}\text { 3. Minor criticism but no } \\
\text { adverse clinical affects. }\end{array}$ & 4. Desire for improvement. & \multirow{4}{*}{$\begin{array}{c}\text { 5. Completely } \\
\text { dissatisfied and/or } \\
\text { adverse effects, including } \\
\text { pain }\end{array}$} \\
\hline & & & 2.1 Esthetics & 3.1 Esthetic shortcomings. & 4.1. Esthetics & \\
\hline & & & $\begin{array}{l}2.2 \text { Function, e.g., minor } \\
\text { roughness }\end{array}$ & $\begin{array}{l}\text { 3.2 Some lack of chewing } \\
\text { comfort. }\end{array}$ & $\begin{array}{l}\text { 4.2 Function, e.g., tongue } \\
\text { irritation. Reshaping } \\
\text { of anatomic form or } \\
\text { refurbishing is possible }\end{array}$ & \\
\hline & & & & $\begin{array}{c}3.3 \text { Unpleasant treatment } \\
\text { procedure }\end{array}$ & & \\
\hline
\end{tabular}




\begin{tabular}{|c|c|c|c|c|c|c|}
\hline \multirow{11}{*}{ 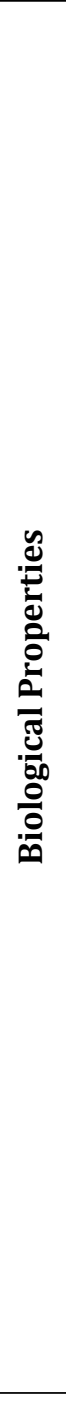 } & \multirow{3}{*}{$\begin{array}{c}\text { Postoperative } \\
\text { (hypersensitivity and } \\
\text { tooth vitality }\end{array}$} & \multirow{3}{*}{$\begin{array}{l}\text { 1. No } \\
\text { hypersensitivity, } \\
\text { normal vitality. }\end{array}$} & \multirow{3}{*}{$\begin{array}{l}\text { 2. Minor hypersensitivity } \\
\text { for a limited period of } \\
\text { time, normal vitality }\end{array}$} & 3.1 Moderate hypersensitivity. & $\begin{array}{c}4.1 \text { Intense } \\
\text { hypersensitivity. }\end{array}$ & \multirow{3}{*}{$\begin{array}{l}\text { 5. Intense, acute pulpitis } \\
\text { or non vital tooth. } \\
\text { Endodontic treatment } \\
\text { is necessary and } \\
\text { restoration has to be } \\
\text { replaced }\end{array}$} \\
\hline & & & & $\begin{array}{l}\text { 3.2 Delayed/mild sensitivity; } \\
\text { no subjective complaints, no } \\
\text { treatment needed }\end{array}$ & $\begin{array}{l}\text { 4.2 Delayed with minor } \\
\text { subjective symptoms. }\end{array}$ & \\
\hline & & & & & $\begin{array}{l}4.3 \text { No clinical detectable } \\
\text { sensitivity. Intervention } \\
\text { necessary but not } \\
\text { replacement } \\
\end{array}$ & \\
\hline & & \multirow{4}{*}{$\begin{array}{l}\text { 1. No secondary or } \\
\text { primary caries }\end{array}$} & 2. Small and localized & 3. Larger areas of & $\begin{array}{c}4.1 \text { Caries with } \\
\text { cavitation and suspected } \\
\text { undermining caries }\end{array}$ & 5. Deep \\
\hline & & & 2.1. Demineralization & 3.1.Demineralization & 4.2 Erosion in dentine & caries or exposed \\
\hline & & & 2.2. Erosion or & 3.2. Erosion or & $\begin{array}{c}4.3 \text { Abrasion/abfraction } \\
\text { in dentine. Localized and } \\
\text { accessible can be repaired. }\end{array}$ & $\begin{array}{l}\text { dentin that is not } \\
\text { accessible for repair of } \\
\text { restoration. }\end{array}$ \\
\hline & & & 2.3. Abfraction & $\begin{array}{c}\text { 3.3. Abrasion/Abfraction,no } \\
\text { dentin exposure. Only } \\
\text { preventive measures } \\
\text { necessary }\end{array}$ & & \\
\hline & \multirow{3}{*}{$\begin{array}{l}\text { Tooth integrity } \\
\text { (enamel cracks, tooth } \\
\text { fractures) }\end{array}$} & 1. Complete & 2.1 Small & $\begin{array}{l}\text { 3.1 Marginal enamel defect } \\
<250 \mu \mathrm{m}\end{array}$ & $\begin{array}{c}4.1 \text { Major marginal } \\
\text { enamel defects; gap > } 250 \\
\mu \mathrm{m} \text { or dentine or base } \\
\text { exposed }\end{array}$ & 5. Cusp or \\
\hline & & integrity & $\begin{array}{c}\text { Marginal enamel } \\
\text { fracture }(<150 \mu \mathrm{m}) .\end{array}$ & 3.2 Crack <250 $\mu \mathrm{m}$; & $\begin{array}{l}\text { 4.2 Large cracks }>250 \mu \mathrm{m}, \\
\text { probe penetrates. }\end{array}$ & tooth fracture \\
\hline & & & $\begin{array}{l}\text { 2.2 Hairline crack in } \\
\text { enamel }(<150 \mu \mathrm{m}) .\end{array}$ & 3.3 Enamel chipping & $\begin{array}{l}\text { 4.3. Large enamel } \\
\text { chipping or wall fracture }\end{array}$ & \\
\hline & Adjacent mucosa & $\begin{array}{l}\text { 1. Healthy mucosa } \\
\text { adjacent to } \\
\text { restoration }\end{array}$ & $\begin{array}{l}\text { 2. Healthy after minor } \\
\text { removal of Mechanical } \\
\text { irritations (plaque, } \\
\text { calculus, sharp edges etc. }\end{array}$ & $\begin{array}{c}\text { 3. Alteration of mucosa } \\
\text { but no suspicion of causal } \\
\text { relationship with restorative } \\
\text { material }\end{array}$ & $\begin{array}{l}\text { 4. Suspected mild allergic, } \\
\text { lichenoid or toxic reaction. }\end{array}$ & $\begin{array}{l}\text { 5. Suspected severe } \\
\text { allergic, lichenoid or } \\
\text { toxic reaction. }\end{array}$ \\
\hline
\end{tabular}

Table 2: Scoring Criteria for Direct Assessment from Modified Hickel Criteria [17]. 
Comparison of these two restorative materials systems in a clinical trial setting provides valuable information for clinicians when selecting optimal materials for best clinical outcomes. BL system offers unique advantages from its filler, giomer for remineralization and antipathogenic effects. It also offers very low shrinkage rate with a reported value below $1 \% \mathrm{v} / \mathrm{v}$ [9]. Potential clinical advantages from these would be stronger bonding strength from less contraction of the restorative material and better marginal seal integrity, which is further benefited by prevention of recurrent caries from fluoride release. Nano sized filler based FS system provides advantages to Class $\mathrm{V}$ restorations in terms of esthetics from superior translucency and shade matching, material strength, wear resistance and polish retention [14]. Hass V reported superior bonding strength from the Scotch bonding system is expected to provide strong bonding of restoration system to the dentin and enamel surface [15].

The purpose of this clinical trial was to evaluate the effectiveness of a new composite resin system in restoring NCCL Class V lesions. In an 18 month split mouth clinical trial, restorations were measured to the survival rate guideline established by the American Dental Association (ADA) Council on Dental Materials at 6 month and 18 month check points [16]. Comprehensive clinical performances were compared following the 5 point scale Modified Hickel Evaluation Criteria (Table 2) [17]. We expected both restoration systems to perform equally under Hickel gradings. Based on our established hypothesis the study's null hypothesis was: H0: Hickel Gradings of BL=Hickel Gradings of FS.

\section{Materials and Methods}

This clinical study was conducted at Tufts University School of Dental Medicine (TUSDM) Research Clinic (Boston, MA) under the Subject Informed Consent Form (ICF) and the Clinical Research Protocol approved by Tufts Medical Center and Tufts University Institutional Review Board \#12486. This 18-month randomized, controlled, split mouth, clinical trial was conducted in 4 visits: screening, restoration placement (0-month), 6-month follow-up and 18-month follow-up where, at the request of the consented subject, screening and restoration visits were sometimes combined into one visit.

A sample size of 50 was calculated to have $80 \%$ power assuming modified Hickel scores for control composite of $50 \%$ of restorations have a score of $1,40 \%$ of restorations have a score of $2,10 \%$ of restorations have a score of 3 , and $0 \%$ of restorations have a score of 4 or 5 at $18-$ months; modified Hickel scores for resin composite of $77.8 \%$ of restorations have a score of $1,22.2 \%$ of restorations have a score of 2 , and $0 \%$ of restorations have a score of 3,4 or 5 at 18 -months; a type I error of 5\%; and a dropout rate of $20 \%$.

\begin{tabular}{|c|c|}
\hline Inclusion Criteria & Exclusion Criteria \\
\hline \multicolumn{2}{|c|}{ Subjects } \\
\hline $\begin{array}{l}\text { Must be } 18 \text { years or older } \\
\text { Must have given written consent to participate in the trial } \\
\text { Must be in good general health } \\
\text { Must be available for the required post-operative follow-up } \\
\text { visits }\end{array}$ & $\begin{array}{c}\text { Does not meet all inclusion criteria } \\
\text { Rampant uncontrolled caries } \\
\text { Systemic or local disorders that contraindicate the dental } \\
\text { procedures included in this study } \\
\text { Evidence of xerostomia } \\
\text { related therapy } \\
\text { Evidence of severe bruxing or clenching or in need of TMJ } \\
\text { Women who are pregnant (self-reported). It is standard of } \\
\text { care to postpone routine dental procedures and radiographs } \\
\text { until after pregnancy } \\
\text { Women who are breast feeding } \\
\text { Known allergy to resin composites or local anesthetics } \\
\text { Abnormal oral soft tissue findings (e.g., open sores, lesions) } \\
\text { Are unwilling or unable to have dental radiographs or } \\
\text { photographs taken of their dentition or soft tissues } \\
\text { Condition affecting salivary flow (e.g., salivary gland disorder, } \\
\text { Sjögren's Syndrome) } \\
\text { Any other condition which in the view of the investigator may } \\
\text { affect the ability of a subject to complete the study }\end{array}$ \\
\hline
\end{tabular}




\section{Restorations}

Must have a minimum of 2 cervical lesions in need of restoration. Subjects with more than 2 cervical lesions may be enrolled but the additional teeth will not be included in the study. In the event that a subject has multiple lesions requiring restorations that meet the study criteria, a randomization scheme will be used to choose the 2 teeth for the study.

Cervical lesions must provide for a minimum of $1 \mathrm{~mm}$ thickness of restorative material while maintaining natural tooth contour

Cervical lesions - at least $50 \%$ of lesion must be in dentin Cervical lesions - coronal margin must be in enamel
Teeth with periapical pathology or exhibiting symptoms of pulpal pathology

Teeth that are non-vital or have had root canal therapy Teeth that have been pulp capped

Teeth with near exposures on pre-operative radiographs Hypersensitive teeth

Teeth with a periodontal pocket of more than $4 \mathrm{~mm}$ with bleeding on probing

Teeth that are used as abutments for removable partial dentures

Table 3: Inclusion/Exclusion Criteria.

The clinical requirements for subject inclusion in this study were as follows (Table 3): Must have a minimum of 2 cervical lesions in need of restoration. Cervical lesions must provide a minimum of $1 \mathrm{~mm}$ thickness of restorative material while maintaining natural tooth contour. At least $50 \%$ of the lesion must be in dentin. Coronal margin must be in enamel.

The key exclusion criteria in this study were as follows: Teeth with periapical pathology or exhibiting symptoms of pulpal pathology were not qualified. Teeth that were nonvital or had root canal therapy, near pulp exposure from radiographs, hypersensitive teeth, advanced periodontal disease and abutments to removable prosthesis were excluded. A complete list of inclusion and exclusion criteria established for this study is presented in Table 3.

Two clinicians (YHK and MLS) placed 98 Class V restorations in 49 subjects. All subjects received two Class V restorations, one randomly selected NCCL restored with BL and the other with FS with both restorations using total-etch method. Compositions of materials used are listed in Table 1. The subjects' ages ranged from 27 to 80 years (mean age, 56 years). All subjects were provided with a written ICF and provided consent via signature in order to participate in the study. For this study, NCCL were prepared in the most conservative form to preserve as much of healthy dentin and enamel structure as possible. Diamond burs (Brasseler USA, Savannah, GA) were first used then finished with non-fluoride pumice to finish the cavity preparations. Isolite (Zyris, Santa Barbara, CA) or Mr Thirsty (Zirc, Buffalo, MN) with cotton rolls were used for isolation. Total-etch method was used for bonding procedure, then assigned composite materials were placed to restore the prepared lesions. Completed restorations were finished and polished with Shofu Super Snap Rainbow Technique Kit. (SHOFU, Kyoto, Japan). Clinical images were taken before, after, and at follow-up visits using EyeSpecial C-II (SHOFU, Kyoto, Japan).
Clinical assessments using modified Hickel Criteria were done by blinded examiners (BEM, DLT, MLS, GK and YHK) other than the examiner that placed the restorations [17]. All examiners were calibrated and trained prior to the start of the study. Efforts were made to have the same examiner examine the same subject at each visit. Restorations were evaluated according to modified clinical criteria by Hickel, et al. including esthetic properties (surface luster, surface staining, marginal staining, color match and anatomical form), functional properties (fracture of material and retention, marginal adaptation, subject's view) and biologic properties (recurrence of caries, tooth integrity, adjacent mucosa) [17]. Evaluation grading criteria are listed in Table 2.

Descriptive statistics were calculated. Differences in modified Hickel Criteria between products were assessed with the Wilcoxon signed-rank test. P-values less than 0.05 were considered statistically significant. All statistical analyses were performed in Stata 13.1 (StataCorp LP, College Station, TX).

\section{Results}

Five clinicians (BEM, DLT, MLS, KG and YHK) evaluated restorations. This split-mouth study started with 49 Subjects each with two restorations placed under the established TUSDM standard of care making total of 98 restorations at baseline visit. At 6-month recall examinations, 90 (91.8\%) restorations were evaluated. At 18-month recall examinations, 74 (75.5\%) restorations were evaluated. At 6-month follow-up, 44 of 45 BL system restorations were intact producing its retention success rate of $97.8 \%$. All 45 FS system restorations presented intact with success rate of $100 \%$. At 18-month follow-up, 39 of 43 (90.7\%) restorations of BL were intact and acceptable and 41 of 43 (95.3\%) restorations of FS were intact and acceptable. 
Clinical evaluations under Hickel Criteria (Table 2) showed similar performances by both material systems compared under the scale of 1 being Clinically excellent/very good to 5 being Clinically poor (replacement necessary). The complete list of Hickel Scores at each recall time period are presented in Table 4 . When comparing the number of cases that scored Clinically Excellent/Very Good rating, both restoration systems performed fairly evenly as well. Figure 1 presents the head-to-head comparisons of occurrence rate (\% of number of cases scored 1$)$ of cases with Clinically
Excellent/Very Good rating. 100\% score 1 occurrence rate was reported in Post-Op Sensitivity, Recurrence of Caries, Erosion and Abfraction and Tooth Integrity categories. Both restorative systems performed evenly in all remaining categories head to head. Notably, Marginal Staining and Marginal Adaptation had occurrences rate at or below $80 \%$, implying that marginal seal under cyclic flexural deformation of tooth deteriorates the bonding between the restoration material and tooth structure.

\begin{tabular}{|c|c|c|c|c|c|c|c|c|c|}
\hline & \multirow{2}{*}{ Hickel Category } & \multirow{2}{*}{ Visits } & \multirow{2}{*}{ Materials } & \multicolumn{6}{|c|}{ Hickel Scoring } \\
\hline & & & & 1 & 2 & 3 & 4 & 5 & NS \\
\hline \multirow{30}{*}{ 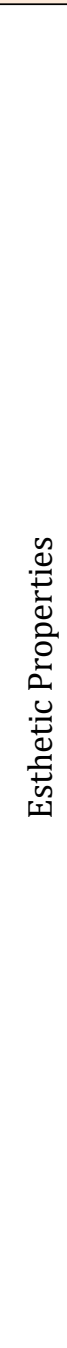 } & \multirow{6}{*}{ Surface Luster } & \multirow{2}{*}{$0 \mathrm{mo}$} & $\mathrm{BL}$ & 49 & & & & & \\
\hline & & & FS & 49 & & & & & \\
\hline & & \multirow{2}{*}{$6 \mathrm{mo}$} & $\mathrm{BL}$ & 40 & 4 & 1 & & & 4 \\
\hline & & & FS & 37 & 7 & 1 & & & 4 \\
\hline & & \multirow{2}{*}{$18 \mathrm{mo}$} & $\mathrm{BL}$ & 37 & & & & & 12 \\
\hline & & & FS & 34 & 3 & & & & 12 \\
\hline & \multirow{6}{*}{ Surface Staining } & \multirow{2}{*}{$0 \mathrm{mo}$} & $\mathrm{BL}$ & 49 & & & & & \\
\hline & & & FS & 49 & & & & & \\
\hline & & \multirow{2}{*}{$6 \mathrm{mo}$} & $\mathrm{BL}$ & 42 & 3 & & & & 4 \\
\hline & & & FS & 39 & 6 & & & & 4 \\
\hline & & \multirow{2}{*}{$18 \mathrm{mo}$} & $\mathrm{BL}$ & 32 & 4 & 1 & & & 12 \\
\hline & & & FS & 31 & 5 & 1 & & & 12 \\
\hline & \multirow{6}{*}{ Margin Staining } & \multirow{2}{*}{$0 \mathrm{mo}$} & BL & 49 & & & & & \\
\hline & & & FS & 48 & 1 & & & & \\
\hline & & \multirow{2}{*}{$6 \mathrm{mo}$} & $\mathrm{BL}$ & 40 & 5 & & & & 4 \\
\hline & & & FS & 41 & 4 & & & & 4 \\
\hline & & \multirow{2}{*}{$18 \mathrm{mo}$} & $\mathrm{BL}$ & 25 & 11 & 1 & & & 12 \\
\hline & & & FS & 23 & 11 & 3 & & & 12 \\
\hline & \multirow{6}{*}{ Color Match and Translucency } & \multirow{2}{*}{$0 \mathrm{mo}$} & $\mathrm{BL}$ & 46 & 3 & & & & \\
\hline & & & FS & 44 & 5 & & & & \\
\hline & & \multirow{2}{*}{$6 \mathrm{mo}$} & $\mathrm{BL}$ & 36 & 8 & 1 & & & 4 \\
\hline & & & FS & 31 & 13 & 1 & & & 4 \\
\hline & & \multirow{2}{*}{$18 \mathrm{mo}$} & $\mathrm{BL}$ & 31 & 6 & & & & 12 \\
\hline & & & FS & 28 & 8 & 1 & & & 12 \\
\hline & \multirow{6}{*}{ Esthetic Anatomical Form } & \multirow{2}{*}{0 mo } & $\mathrm{BL}$ & 48 & 1 & & & & \\
\hline & & & FS & 49 & & & & & \\
\hline & & \multirow{2}{*}{$6 \mathrm{mo}$} & $\mathrm{BL}$ & 45 & & & & & 4 \\
\hline & & & FS & 42 & 2 & 1 & & & 4 \\
\hline & & \multirow{2}{*}{$18 \mathrm{mo}$} & $\mathrm{BL}$ & 38 & & & & 4 & $7 *$ \\
\hline & & & FS & 39 & 1 & & & 2 & $7 *$ \\
\hline & & $0 \mathrm{mo}$ & $\mathrm{BL}$ & 49 & & & & & \\
\hline & & $0 \mathrm{mo}$ & FS & 49 & & & & & \\
\hline & & & $\mathrm{BL}$ & 45 & & & & & 4 \\
\hline & Fracture of Material and Retention & $6 \mathrm{mo}$ & FS & 45 & & & & & 4 \\
\hline & & & $\mathrm{BL}$ & 37 & & 1 & & 4 & $7 *$ \\
\hline & & $18 \mathrm{mo}$ & FS & 40 & & & & 2 & $7^{*}$ \\
\hline
\end{tabular}


Open Access Journal of Dental Sciences

\begin{tabular}{|c|c|c|c|c|c|c|c|c|}
\hline \multirow{18}{*}{ 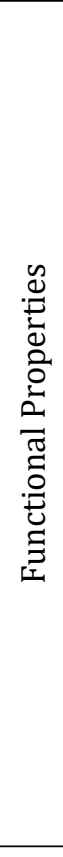 } & \multirow{6}{*}{ Marginal Adaptation } & \multirow{2}{*}{$0 \mathrm{mo}$} & BL & 49 & & & & \\
\hline & & & $\mathrm{FS}$ & 49 & & & & \\
\hline & & \multirow{2}{*}{$6 \mathrm{mo}$} & $\mathrm{BL}$ & 36 & 7 & 2 & & 4 \\
\hline & & & FS & 34 & 9 & 2 & & 4 \\
\hline & & \multirow{2}{*}{$18 \mathrm{mo}$} & $\mathrm{BL}$ & 29 & 6 & 2 & & 12 \\
\hline & & & FS & 31 & 5 & 1 & & 12 \\
\hline & \multirow{6}{*}{ Radiographic Examination } & \multirow{2}{*}{$0 \mathrm{mo}$} & BL & & & & & 49 \\
\hline & & & FS & & & & & 49 \\
\hline & & \multirow{2}{*}{$6 \mathrm{mo}$} & $\mathrm{BL}$ & & & & & 49 \\
\hline & & & FS & & & & & 49 \\
\hline & & \multirow{2}{*}{$18 \mathrm{mo}$} & $\mathrm{BL}$ & & & & 1 & $10 \#$ \\
\hline & & & FS & & & & 2 & $10 \#$ \\
\hline & \multirow{6}{*}{ Patient's View } & \multirow{2}{*}{$0 \mathrm{mo}$} & $\mathrm{BL}$ & 49 & & & & \\
\hline & & & $\mathrm{FS}$ & 49 & & & & \\
\hline & & \multirow{2}{*}{$6 \mathrm{mo}$} & $\mathrm{BL}$ & 45 & & & & 4 \\
\hline & & & FS & 44 & 1 & & & 4 \\
\hline & & \multirow{2}{*}{$18 \mathrm{mo}$} & $\mathrm{BL}$ & 47 & & & & $7 *$ \\
\hline & & & $\mathrm{FS}$ & 42 & & & & $7^{*}$ \\
\hline \multirow{24}{*}{ 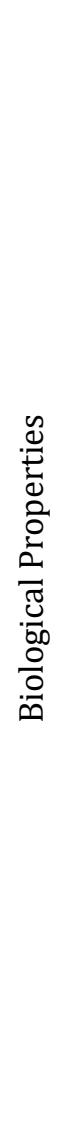 } & \multirow{6}{*}{$\begin{array}{c}\text { Postoperative Sensitivity and } \\
\text { Tooth Vitality }\end{array}$} & \multirow{2}{*}{$0 \mathrm{mo}$} & $\mathrm{BL}$ & & & & & 49 \\
\hline & & & FS & & & & & 49 \\
\hline & & \multirow{2}{*}{$6 \mathrm{mo}$} & $\mathrm{BL}$ & 45 & & & & 4 \\
\hline & & & FS & 45 & & & & 4 \\
\hline & & \multirow{2}{*}{$18 \mathrm{mo}$} & $\mathrm{BL}$ & 42 & & & & $7^{*}$ \\
\hline & & & FS & 42 & & & & $7^{*}$ \\
\hline & \multirow{6}{*}{$\begin{array}{c}\text { Recurrence of Caries, Erosion, } \\
\text { Abfraction }\end{array}$} & \multirow{2}{*}{$0 \mathrm{mo}$} & $\mathrm{BL}$ & 49 & & & & \\
\hline & & & FS & 49 & & & & \\
\hline & & \multirow{2}{*}{$6 \mathrm{mo}$} & BL & 45 & & & & \\
\hline & & & $\mathrm{FS}$ & 45 & & & & \\
\hline & & \multirow{2}{*}{$18 \mathrm{mo}$} & BL & 38 & & & & $11^{\wedge}$ \\
\hline & & & FS & 38 & & & & $11^{\wedge}$ \\
\hline & \multirow{6}{*}{$\begin{array}{c}\text { Tooth Integrity (Enamel Cracks, } \\
\text { Tooth Fractures) }\end{array}$} & \multirow{2}{*}{$0 \mathrm{mo}$} & BL & 49 & & & & \\
\hline & & & FS & 49 & & & & \\
\hline & & $6 \mathrm{mo}$ & $\mathrm{BL}$ & 45 & & & & 4 \\
\hline & & o mo & FS & 45 & & & & 4 \\
\hline & & $18 \mathrm{mo}$ & BL & 38 & & & & $11^{\wedge}$ \\
\hline & & $18 \mathrm{mo}$ & FS & 38 & & & & $11^{\wedge}$ \\
\hline & & $0 \mathrm{mo}$ & BL & 49 & & & & \\
\hline & & III0 & FS & 49 & & & & \\
\hline & & & BL & 40 & 3 & 2 & & 4 \\
\hline & Adjacent Mucosa & o mo & FS & 42 & & 3 & & 4 \\
\hline & & $18 \mathrm{mo}$ & $\mathrm{BL}$ & 38 & 3 & & & 8* \\
\hline & & $18 \mathrm{mo}$ & FS & 40 & 1 & & & $8^{*}$ \\
\hline
\end{tabular}

*,^: Partial categories scored due to missing restorations when they presented for the 18 months follow-up visit.

\#: Subject 1024 Pregnant, no radiographs taken

Table 4: Complete list of Hickel Scoring results. 


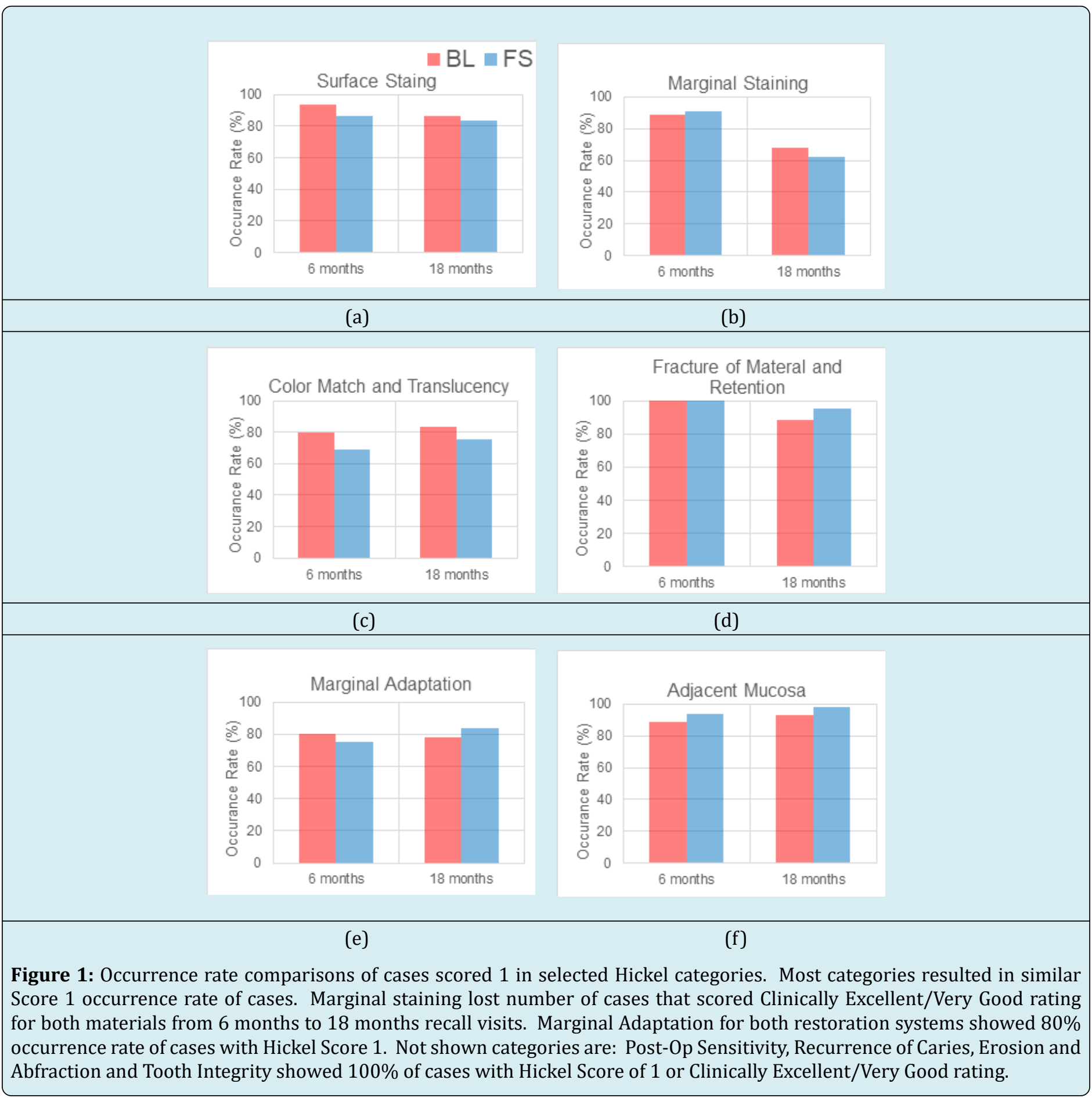

Performance comparisons of two restoration material systems were analyzed with the Wilcoxon signed-rank test. The test was only performed on subjects having both restorations intact with the established hypothesis: BL and FS will perform equally in Hickel Scoring $(\mathrm{H0}$ : BL = FS). P-value of 1 was reported when categories with all of the scores were the same for both restorations. Table 5 presents the statistical ranking results in each clinical criterion and the number of cases that scored superior Hickel score or performed equally. $\mathrm{P}$-value of less than 0.05 represented statistical significance. No categories showed statistically significant differences. Clinical presentations of both restoration systems compared similarly at each recall visit time point. Representative clinical photographs taken for both BL and FS at each visit are presented in Figures 2-7. 
Open Access Journal of Dental Sciences

\begin{tabular}{|c|c|c|c|}
\hline \multicolumn{4}{|c|}{ Surface Luster } \\
\hline & 0 month & 6 months & 18 months \\
\hline $\mathrm{BL}$ & 0 & 2 & 0 \\
\hline FS & 0 & 5 & 3 \\
\hline Equal & 49 & 38 & 32 \\
\hline $\mathrm{z}$ value & $n / a, p=1$ & 0.257 & 0.083 \\
\hline \multicolumn{4}{|c|}{ Surface Stain } \\
\hline & 0 month & 6 months & 18 months \\
\hline $\mathrm{BL}$ & 0 & 1 & 1 \\
\hline FS & 0 & 4 & 2 \\
\hline Equal & 49 & 40 & 32 \\
\hline p value & $\mathrm{n} / \mathrm{a}, \mathrm{p}=\mathbf{1}$ & 0.18 & 0.564 \\
\hline \multicolumn{4}{|c|}{ Marginal Stain } \\
\hline & 0 month & 6 months & 18 months \\
\hline $\mathrm{BL}$ & 0 & 3 & 3 \\
\hline FS & 1 & 2 & 7 \\
\hline Equal & 48 & 40 & 25 \\
\hline p value & 0.313 & 0.655 & 0.206 \\
\hline \multicolumn{4}{|c|}{ Color Match and Translucency } \\
\hline & 0 month & 6 months & 18 months \\
\hline $\mathrm{BL}$ & 2 & 5 & 1 \\
\hline FS & 4 & 10 & 4 \\
\hline Equal & 43 & 30 & 30 \\
\hline p value & 0.414 & 0.197 & 0.176 \\
\hline \multicolumn{4}{|c|}{ Esthetic Anatomical Form } \\
\hline & 0 month & 6 months & 18 months \\
\hline BL & 1 & 0 & 3 \\
\hline FS & 0 & 3 & 2 \\
\hline Equal & 48 & 42 & 35 \\
\hline p value & 0.317 & 0.083 & 0.63 \\
\hline \multicolumn{4}{|c|}{ Fracture of Material and Retention } \\
\hline & 0 month & 6 months & 18 months \\
\hline $\mathrm{BL}$ & 0 & 0 & 4 \\
\hline FS & 0 & 0 & 1 \\
\hline Equal & 49 & 45 & 35 \\
\hline p value & $n / a, p=1$ & $n / a, p=1$ & 0.184 \\
\hline \multicolumn{4}{|c|}{ Marginal Adaptation } \\
\hline & 0 month & 6 months & 18 months \\
\hline $\mathrm{BL}$ & 1 & 3 & 4 \\
\hline FS & 0 & 5 & 1 \\
\hline
\end{tabular}




\begin{tabular}{|c|c|c|c|}
\hline Equal & 48 & 37 & 30 \\
\hline p value & 0.317 & 0.48 & 0.18 \\
\hline \multicolumn{4}{|c|}{ Radiographic Examination (when applicable) } \\
\hline & 0 month & 6 months & 18 months \\
\hline BL & $\mathrm{n} / \mathrm{a}$ & $\mathrm{n} / \mathrm{a}$ & 1 \\
\hline FS & $\mathrm{n} / \mathrm{a}$ & $\mathrm{n} / \mathrm{a}$ & 1 \\
\hline Equal & $\mathrm{n} / \mathrm{a}$ & $\mathrm{n} / \mathrm{a}$ & 35 \\
\hline p value & $\mathbf{n} / \mathbf{a}$ & $\mathbf{n} / \mathbf{a}$ & 0.985 \\
\hline \multicolumn{4}{|c|}{ Patient's View } \\
\hline & 0 month & 6 months & 18 months \\
\hline BL & 0 & 0 & 0 \\
\hline FS & 0 & 1 & 0 \\
\hline Equal & 49 & 44 & 40 \\
\hline p value & $\mathbf{n} / \mathbf{a}, \mathbf{p}=\mathbf{1}$ & 0.317 & $\mathbf{n} / \mathbf{a}, \mathbf{p}=\mathbf{1}$ \\
\hline \multicolumn{4}{|c|}{ Postoperative (Hyper-)Sensitivity and Tooth Vitality } \\
\hline & 0 month & 6 months & 18 months \\
\hline $\mathrm{BL}$ & $\mathrm{n} / \mathrm{a}$ & 0 & 0 \\
\hline FS & $\mathrm{n} / \mathrm{a}$ & 0 & 0 \\
\hline Equal & $\mathrm{n} / \mathrm{a}$ & 45 & 40 \\
\hline p value & $\mathbf{n} / \mathbf{a}$ & $\mathrm{n} / \mathrm{a}, \mathrm{p}=\mathbf{1}$ & $\mathbf{n} / \mathbf{a}, \mathbf{p}=\mathbf{1}$ \\
\hline \multicolumn{4}{|c|}{ Recurrence of Caries, Erosion, Abfraction } \\
\hline & 0 month & 6 months & 18 months \\
\hline $\mathrm{BL}$ & 0 & 0 & 0 \\
\hline FS & 0 & 0 & 0 \\
\hline Equal & 49 & 45 & 36 \\
\hline p value & $\mathbf{n} / \mathbf{a}, \mathbf{p}=\mathbf{1}$ & $\mathrm{n} / \mathrm{a}, \mathrm{p}=\mathbf{1}$ & $\mathrm{n} / \mathrm{a}, \mathrm{p}=\mathbf{1}$ \\
\hline \multicolumn{4}{|c|}{ Tooth Integrity (Enamel Cracks, Tooth Fractures) } \\
\hline & 0 month & 6 months & 18 months \\
\hline $\mathrm{BL}$ & 0 & 0 & 0 \\
\hline FS & 0 & 0 & 0 \\
\hline Equal & 49 & 45 & 36 \\
\hline p value & $\mathbf{n} / \mathbf{a}, \mathbf{p}=\mathbf{1}$ & $\mathbf{n} / \mathbf{a}, \mathbf{p}=\mathbf{1}$ & $\mathbf{n} / \mathbf{a}, \mathbf{p}=\mathbf{1}$ \\
\hline \multicolumn{4}{|c|}{ Adjacent Mucosa } \\
\hline & 0 month & 6 months & 18 months \\
\hline $\mathrm{BL}$ & 0 & 3 & 2 \\
\hline FS & 0 & 1 & 0 \\
\hline Equal & 49 & 41 & 37 \\
\hline p value & $\mathrm{n} / \mathrm{a}, \mathrm{p}=\mathbf{1}$ & 0.334 & 0.157 \\
\hline
\end{tabular}

Table 5: The Wilcoxon signed-rank test results are presented in p-values. Table also presents the number of cases scored equal or higher in head-to-head comparisons within a same subject. 


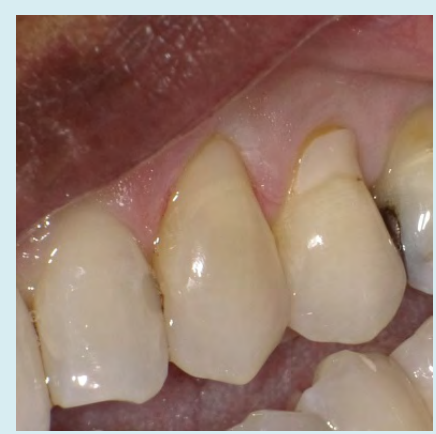

Figure 2: Baseline postoperative photograph of FS \#11.

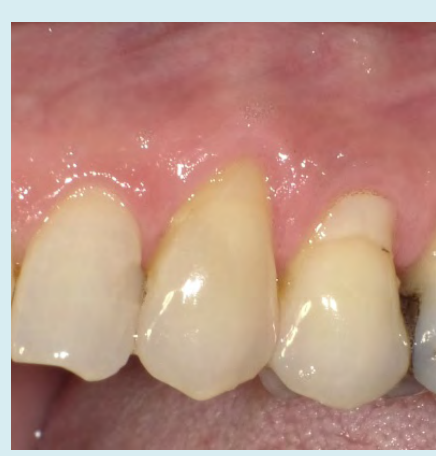

Figure 3: Photograph of FS \#11 at 6 months recall.

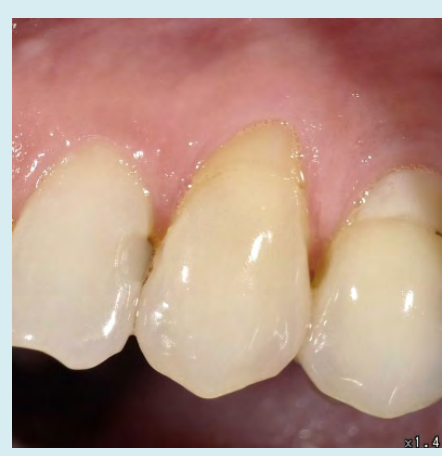

Figure 4: Photograph of FS \#11 at 18 months recall.

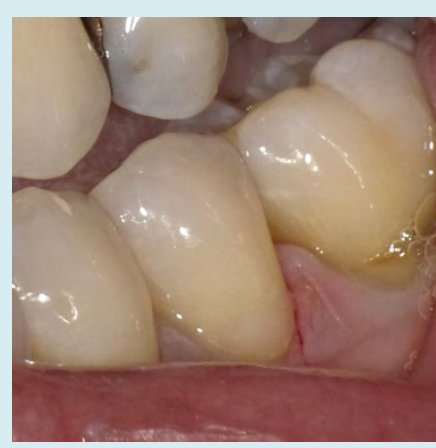

Figure 5: Baseline postoperative photograph of BL \#20.

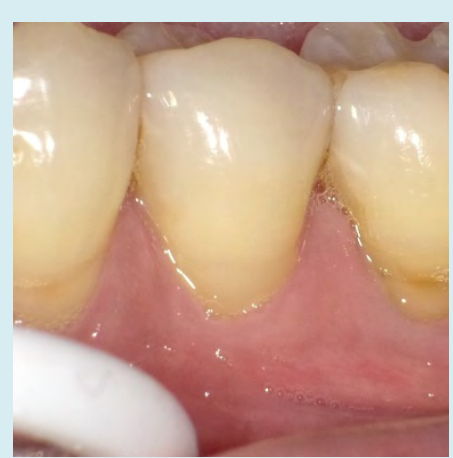

Figure 6: Photograph of $\mathrm{BL} \# 20$ at 6 months recall.

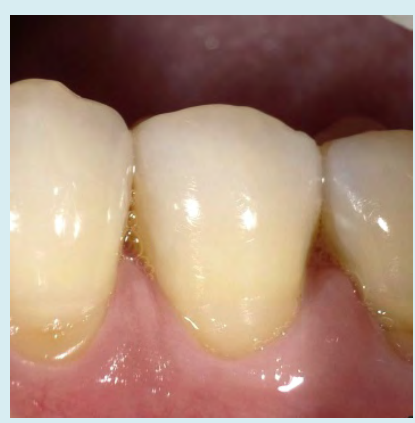

Figure 7: Photograph of BL \#20 at 18 months recall.

\section{Discussion}

This split-mouth study compared clinical performance of two different restorative materials used to restore NCCL as Class V restorations. The study subjects were screened to insure good general health and absence of any medical conditions that could potentially affect the performance of the materials, such dry mouth caused by Sjogren's Syndrome or history of radiation treatments in the head and neck area. A comprehensive oral examination was conducted including gingiva inflammation level via gingival index scale (Löe-Silness Index) [18], recession, clinical attachment level, probing pocket depth, and calculus exam via VolpeManhold method [19], to confirm the participant was in good periodontal health and ensure severity of poor periodontal health would not be a factor affecting restoration condition.

The subject recall rate at 6 months was $93.9 \%$ and at 18 months was $87.8 \%$. The recall rate of $87.8 \%$ exceeded the study's goal of retaining $80 \%$ or higher recall rate for statistical comparison validity. However, there were subjects who presented with only one restoration intact. At the 6-month recall, one subject presented with lost BL only and at 18-month recall, 4 subjects presented with lost BL only and two subjects with only lost FS. Examiners scored categories, that could be scored without restorations intact, even when a subject presented with only one restoration intact for the 


\section{Open Access Journal of Dental Sciences}

recall exam. As a result, Hickel criteria that require presence of intact restorations were not scored while non-restoration involving categories under Biological Properties were evaluated as partial category scoring. However, only subjects that retained both restorations were used for statistical comparisons.

The restoration retention (survival) rate reported in this study at the 6-month recall was $97.8 \%$ for BL system and $100 \%$ for FS system, and at 18 -month recall, was $90.7 \%$ for BL system and $95.3 \%$ for FS system. The ADA guidelines established 'provisional acceptance' retention rate of $95 \%$ at 6 months and 'full acceptance' for $90 \%$ at 18 months after the completion of restorations [16]. Therefore in this clinical trial, both restoration materials system met the recommended acceptance level. The retention level reported in this study is also comparable to the values reported by previous studies. One clinical study reported traditional composite/bonding system with 6 months at $89 \%$ and 12 months at $85.7 \%$, with resin modified glass ionomer system with 6 months at $100 \%$ and 12 month at 100\% [7]. Another Class V trial with resin composite materials reported 5-year and 10 -year survival rates of $95.5 \%$ and $83.1 \%$, respectively [20]. A study comparing different bonding agents with resin composite material reported the 2 year retention rates for Clearfil SE Bond at 93\%, and 91\% for Prime \& Bond NT [21]. A similar bonding agent study by van Dijken et al. reported Fuji II LC survival, at 1 year at 98\% [22]. A study by Canali, et al. reported retention rate of Filtek Supreme Class V restorations at $98.9 \%$ at 6 months recall and also $98.9 \%$ at 12 months recall [23].

The reported results from this study is comparable to the previously reported values, which were widely scattered, ranging from $83 \%$ to $100 \%$. Varying retention rate of Class $\mathrm{V}$ restorations could be due to the nature of how lesions are prepared. NCCL restorations, unlike Class I and II restorations, cannot afford to create sufficient retention form, resulting in less than ideal mechanical retention and relying predominantly on the bond strength of the restorative material to enamel and dentin surface. Integrity of marginal seal in Class $\mathrm{V}$ restoration offers an important role of preserving bonding between restorative materials and enamel and dentin surface [7]. Marginal Staining from Hickel evaluation reflects the microleakage of margins, and further deterioration of marginal integrity is reflected in Marginal Adaptation. In this study, both materials performed similarly with no statistical significances in these two categories. From Table 4, the Hickel score results in Marginal Staining category at the 6-month recall, for BL, 88.9\% scored 1 and $11.1 \%$ received score 2 , where for FS $97.6 \%$ scored 1 and $8.9 \%$ received score 2 . At 18 -month recall, $67.6 \%$ of BL received $1,29.7 \%$ received 2 and $2.7 \%$ of cases received score of 3. For FS at 18 months, $62.2 \%$ of cases scored 1, 29.7\% scored 2 and $8.1 \%$ of cases scored 3. Similar observations are reported in Marginal Adaptation evaluations. For BL, at 6 months, score distributions were $80.0 \%$ at $1,15.6 \%$ at 2 and $4.4 \%$ at 3 and at 18 months, $78.4 \%$ at $1,16.2 \%$ at 2 and $5.4 \%$ at 3. Distribution is very similar with FS at 6 months, $75.6 \%$ at $1,20 \%$ at 2 and $4.4 \%$ at 3 . At the 18-month recall FS score distributions were, $83.8 \%$ at $1,13.5 \%$ at 2 and $2.7 \%$ at 3 . Wilcoxon signed-rank test showed no statistical significances in Hickel scoring under these categories. Early marginal seal deterioration in a Class $\mathrm{V}$ lesion could be a combination of biochemical origin from caries inducing bacteria and mechanical stress in forms of flexural motion created from occlusion and bruxism [3]. Prevention of secondary caries at the margins and improved marginal adaptation can therefore, improve the overall retention rate of Class $\mathrm{V}$ restorations. The ion releasing capability of the S-PRG filler in BL fillers can potentially prevent caries from continuous release of multi ions, thus potentially preventing secondary caries originating at the restoration margins along the gingival line [24-26]. This is a very beneficial clinical advantage in NCCL cases in populations with dry mouth conditions due to intake of multiple medications, systemic conditions such as Sjogren's Syndrome, or from a history of head and neck radiation therapy, causing less salivary production and flow. One of the biggest limitations of light curing composite resin material is polymerization shrinkage, especially at the tooth-composite interface [27-30]. Labella $\mathrm{R}$ reported values of post-polymerization volumetric shrinkage range from 1.9 to $13.5 \%$ [31]. With reported shrinkage of only $0.85 \%$ for $\mathrm{BL}$ (compared to $2 \%$ for $\mathrm{FS}$ ), the restoration system incorporates less residual stress at the interface resulting in more secure interfacial bonding to enamel and dentin $[9,12]$. Another advantage is potential bioactive bonding formation. Key ion releasing of S-PRG fillers have been reported to form potential bioactive bonding to dentin surface via mineral induction $[25,32,33]$.

Color Match and Translucency is another important clinical category for Class $\mathrm{V}$ restorations. Restored lesions are located mostly in high visibility areas, therefore, matching or mismatching of shade is readily noticeable. The Hickel evaluation from this study was impartially inconsistent for both restoration systems due to the operator and examiner's subjective standard influences, despite established grading standard and pre-study examiner calibrations. For example, at baseline, after the operator had chosen a shade and placed the restoration, the evaluator sometimes scored the color match as less than 1 . Three scored 2 for BL and 5 scored 2 for FS reflecting the subjective nature of shade selection ability and evaluation standard between the operator and evaluator. One of the significant advantages of nanocomposites like FS is a capability of providing improved esthetics with natural appearances [34]. Another advantage is high resistance to micro-abrasion, which helps restorations from collecting 
staining as restoration ages in patients [35].

Hickel Criteria gradings head-to-head comparisons showed similar performances between the two restorative materials. The comparison results are composed by the number of cases that outperformed one over the other or tied, in terms of Hickel scores from a same subject, and are summarized in Table 6 . At all-time points, there were 16 tied Hickel categories, 8 categories that had BL scored higher and 12 categories that FS scored higher. All comparisons between restoration materials showed performance differences not substantial enough to show statistical significance. Based on this result, we accept the study's null hypothesis: H0: Hickel Gradings of BL $=$ Hickel Gradings of FS.

\begin{tabular}{|c|c|c|c|}
\hline & O month & 6 months & 18 months \\
\hline Surface Luster & $=$ & FS & FS \\
\hline Surface Stain & $=$ & FS & FS \\
\hline Marginal Stain & FS & BL & FS \\
\hline Color Match and Translucency & FS & FS & FS \\
\hline Esthetic Anatomical Form & $\mathrm{BL}$ & FS & BL \\
\hline Fracture of Material and Retention & $=$ & $=$ & $\mathrm{BL}$ \\
\hline Marginal Adaptation & $\mathrm{BL}$ & FS & BL \\
\hline Radiographic Examination (when applicable) & $\mathrm{n} / \mathrm{a}$ & $\mathrm{n} / \mathrm{a}$ & $=$ \\
\hline Patient's View & $=$ & FS & $=$ \\
\hline Postoperative (Hyper-)Sensitivity and Tooth Vitality & $\mathrm{n} / \mathrm{a}$ & $=$ & $=$ \\
\hline Recurrence of Caries, Erosion, Abfraction & $=$ & $=$ & $=$ \\
\hline Tooth Integrity (Enamel Cracks, Tooth Fractures) & $=$ & $=$ & $=$ \\
\hline Adjacent Mucosa & $=$ & BL & $\mathrm{BL}$ \\
\hline
\end{tabular}

Table 6: Below presents which material performed better in head-to-head comparison. FS denotes Filtek Supreme had more subjects with better score. BL denotes BeautifiI II LS had more subjects with better score. = means both materials tied.

Some limitations in this study are as follows. The initial goal was established to prove both materials would perform similarly among a low caries risk population with no comorbidities that could contribute to deterioration of restorations. Under the benign conditions, performance differences of restoration materials may not show readily. Under more strenuous caries inducing conditions, the comparisons could reveal clear differences between the restorations. Another limitation is the length of the study. A longer study of 36,48 or 60 months could reveal more distinct characteristics of the restorative materials. Based on the aforementioned limitations of the study, a future clinical trial evaluating the anti-root caries effect of giomer specific in an elderly population with a dry mouth condition could be clinically valuable. A significant decrease in the flow of saliva, especially during sleeping, results in lower $\mathrm{pH}$ along the gingival lines which leads to root caries. This condition is common among the elderly population due to certain medications, some specific xerostomia causing conditions such as Sjogren's syndrome, and can be caused by something as simple as dehydration and slowed overall physiological function due to aging. Conventional resin based composite restorations fail prematurely in these cases, and use of resin modified glass ionomer materials has shown better prevention of root caries [7]. A giomer based resin restoration could be an effective restorative material option for the prevention and management of root caries.

\section{Conclusion}

The results of this split-mouth 18-month clinical study showed that nanohybrid composite with S-PRG filler, Shofu Beautifil II LS clinically performed similarly in modified Hickel Criteria [17] when compared to nanocomposite 3M Filtek Supreme with no statistically significant differences in any category evaluated.

Disclosure: Shofu (Kyoto, Japan), the manufacturer of Beautifil II LS restorative material and BeautiBond bonding system, provided financial support for this research. None of the authors reported any other disclosures.

Acknowledgement: Authors are grateful to the research coordinators, Courtney Thurell, Christie Mctigue, Sarah Anderson, Noe Duenas, Joseph Cimmino and Liz Tzavaras for their dedication and valuable assistance conducting in this clinical trial. 


\section{References}

1. Levitch LC, Bader JD, Shugars DA, Heymann HO (1994) Non-carious cervical lesions. Journal of Dentistry 22(4): 195-207.

2. Winstanley RB (1986) The treatment of attrition, abrasion and erosion. Restorative Dent 2(1): 5-7, 9-10.

3. Lee WC, Eakle WS (1996) Stress-induced cervical lesions: review of advances in the past 10 years. J Prosthet Dent 75(5): 487-494.

4. Poynter ME, Wright PS (1990) Tooth wear and some factors influencing its severity. Restorative Dent 6(4): 8-11.

5. Braem M, Lambrechts P, Vanherle G (1992) Stressinduced cervical lesions. The Journal of Prosthetic Dentistry 67(5): 718-722.

6. Franco EB, Benetti AR, Ishikiriama SK, Santiago SL, Lauris JRP, et al. (2006) 5-year clinical performance of resin composite versus resin modified glass ionomer restorative system in non-carious cervical lesions. Oper Dent 31(4): 403-408.

7. Santiago SL, Passos VF, Vieira AHM, Navarro MFL, Lauris JRP, et al. (2010) Two-year clinical evaluation of resinous restorative systems in non-carious cervical lesions. Brazilian Dental Journal 21(3): 229-234.

8. Shofu (2019) Beautifil II LS Safety Data Sheet.

9. Shofu (2021) Beautifil II and Beautifil II LS.

10. Shofu (2021) Giomer Technology.

11. Padovani GC, Feitosa VP, Sauro S, Tay FR, Durán G, et al. (2015) Advances in Dental Materials through Nanotechnology: Facts, Perspectives and Toxicological Aspects. Trends Biotechnol 33(11): 621-636.

12. (2010) Filtek Supreme Ultra Technical Product Profile. St. Paul, MN.

13. 3M Science Applied to life (2016) $3 \mathrm{M}^{\mathrm{TM}}$ Scotchbond ${ }^{\mathrm{TM}}$ Universal Adhesive: Technical Product Profile.

14. (2013) 3M ESPE's Filtek ${ }^{\mathrm{TM}}$ Supreme Ultra: offering clinicians exceptional strength, esthetics, and handling. Compend Contin Educ Dent 34(5): 372.

15. Hass V, Cardenas AFM, Siqueira FSF, Pacheco RR, Zago PMW, et al. (2019) Bonding Performance of Universal Adhesive Systems Applied in Etch-and-Rinse and SelfEtch Strategies on Natural Dentin Caries. Oper Dent
44(5): 510-520.

16. Council on Dental Materials, Instruments and Equipment (US), American Dental Association (1994) Revised American Dental Association acceptance program guidelines for dentin and enamel adhesive materials. Chicago, Ill.: American Dental Association, Council on Dental Materials, Instruments and Equipment.

17. Hickel R, Peschke A, Tyas M, Mjör I, Bayne S, et al. (2010) FDI World Dental Federation: clinical criteria for the evaluation of direct and indirect restorations-update and clinical examples. Clin Oral Investig 14(4): 349-366.

18. Loe $H$ (1967) The Gingival Index, the Plaque Index and the Retention Index Systems. J Periodontol 38(6): 610616.

19. Volpe AR, Manhold JH, Hazen SP (1965) In Vivo Calculus Assessment. I. A Method And Its Examiner Reproducibility. J Periodontol 36: 292-298.

20. Kim JH, Cho J, Lee Y, Cho BH (2017) The Survival of Class V Composite Restorations and Analysis of Marginal Discoloration. Oper Dent 42(3): 93-101.

21. Türkün SL (2003) Clinical evaluation of a self-etching and a one-bottle adhesive system at two years. J Dent 31(8): 527-534.

22. van Dijken JW (2000) Clinical evaluation of three adhesive systems in class $\mathrm{V}$ non-carious lesions. Dent Mater 16(4): 285-291.

23. Canali GD, Ignácio SA, Rached RN, Souza EM (2019) Oneyear clinical evaluation of bulk-fill flowable vs. regular nanofilled composite in non-carious cervical lesions. Clin Oral Investig 23(2): 889-897.

24. Scougall Vilchis RJ, Yamamoto S, Kitai N, Hotta M, Yamamoto K (2007) Shear bond strength of a new fluoride-releasing orthodontic adhesive. Dent Mater J 26(1): 45-51.

25. Iijima Y, Koulourides $T$ (1989) Fluoride incorporation into and retention in remineralized enamel. J Dent Res 68(8): 1289-1292.

26. Han L, Edward CV, Li M, Niwano K, Neamat AB, etal. (2002) Effect of fluoride mouth rinse on fluoride releasing and recharging from aesthetic dental materials. Dent Mater J 21(4): 285-295.

27. Davidson CL, Feilzer AJ (1997) Polymerization shrinkage and polymerization shrinkage stress in polymer-based restoratives. J Dent 25(6): 435-440. 
28. Dewaele M, Boutry DT, Devaux J, Leloup G (2006) Volume contraction in photocured dental resins: The shrinkageconversion relationship revisited. Dent Mater 22(4): 359-365.

29. Park J, Chang J, Ferracane J, Lee B (2008) How should composite be layered to reduce shrinkage stress: Incremental or bulk filling? Dent Mater 24(11): 15011505.

30. Truffier Boutry D, Champagne SD, Devaux J, Biebuyck JJ, Mestdagh M, etal. (2006) A physico-chemical explanation of the post-polymerization shrinkage in dental resins. Dent Mater 22(5): 405-412.

31. Labella R, Lambrechts $P, B$ Van Meerbeek, Vanherle G (1999) Polymerization shrinkage and elasticity of flowable composites and filled adhesives. Dent Mater 15(2): 128-137.
32. Featherstone JD, Shields CP, Khademazad B, Oldershaw MD (1983) Acid reactivity of carbonated apatites with strontium and fluoride substitutions. J Dent Res 62(10): 1049-1053.

33. Ito $\mathrm{S}$, Iijima $\mathrm{M}$, Hashimoto $\mathrm{M}$, Tsukamoto $\mathrm{N}$, Mizoguchi $\mathrm{I}$, et al. (2011) Effects of surface pre-reacted glass-ionomer fillers on mineral induction by phosphoprotein. J Dent 39(1): 72-79.

34. Chen MH (2010) Update on dental nanocomposites. J Dent Res 89(6): 549-560.

35. Gordan VV, Blaser PK, Watson RE, Mjör IA, McEdward DL, et al. (2014) A clinical evaluation of a giomer restorative system containing surface prereacted glass ionomer filler: results from a 13-year recall examination. J Am Dent Assoc 145(10): 1036-1043. 